This is the last draft sent to the Editorial by the authors of the article:

M. GÓMEZ, L. RANCEL, S.F. MEDINA

"Assessment of Austenite Static Recrystallization and Grain Size Evolution during Multi-Pass Hot Rolling of a NiobiumMicroalloyed Steel"

Metals and Materials International

Vol. 15 (2009), Pages: 689-699

DOI: 10.1007/s12540-009-0689-0

ISSN: 1598-9623

To be published in Digital.CSIC, the Institutional Repository of the Spanish National Research Council (CSIC)

See more papers from the authors on:

$\underline{\text { http://digital.csic.es }}$

http://www.researcherid.com/rid/B-7922-2008 


\title{
Assessment of Austenite Static Recrystallization and Grain Size Evolution during Multi-Pass Hot Rolling of a Niobium-Microalloyed
}

Steel

\section{Manuel Gómez ${ }^{*}$ Lucía Rancel, Sebastián F. Medina ${ }^{1}$}

National Center for Metallurgical Research, (CENIM-CSIC), Av. Gregorio del Amo 8, 28040 Madrid, Spain.

*Corresponding author: mgomez@cenim.csic.es

${ }^{1}$ smedina@cenim.csic.es

\begin{abstract}
Double-deformation isothermal tests and multipass continuous-cooling hot torsion tests were used to study the evolution of austenite microstructure under isothermal and nonisothermal hot deformation of a Nb microalloyed steel. Thanks to these tests and with the assistance of microstructural characterization, it has been verified that norecrystallization temperature $\left(T_{\mathrm{nr}}\right)$ approximately corresponds to the temperature where recrystallization starts to be incomplete during rolling. An accurate method to estimate the recrystallized fraction during hot rolling from stress-strain data and with no need of metallographic studies is proposed. The results of this method have been successfully compared to metallographic measurements, the values of non-isothermal fractional
\end{abstract}


softening and the accumulated stress measured in the plots of mean flow stress (MFS) versus the inverse of temperature. A remarkable austenite grain refinement occurs in the first hot rolling passes after reheating. If the effect of grain size on recrystallization and precipitation is taken into account, the correlation of isothermal and continuous cooling tests is better understood.

\section{Keywords}

Microalloyed steels; Hot rolling; Static recrystallization; Austenite grain size; Nonisothermal Softening.

\section{INTRODUCTION}

The static recrystallization of microalloyed steels after hot deformation can be hindered by the pinning effect exerted by strain-induced precipitates. In the curves that represent the recrystallized fraction $\left(X_{\mathrm{a}}\right)$ against post-deformation isothermal holding time $\left(\left(X_{\mathrm{a}}(\mathrm{t})\right)\right.$, the inhibition of recrystallization by precipitates is manifested by the formation of a plateau that temporarily interrupts the typical sigmoidal shape of an Avrami's law [1-3]:

$$
X_{a}=1-\exp \left(-\ln 2\left(\frac{t}{t_{0.5}}\right)^{n}\right)
$$

where the exponent $n$ varies with temperature and $t_{0.5}$ is the time corresponding to a recrystallized volume fraction of $50 \%$, which depends on temperature $T$, equivalent pass 
strain $(\varepsilon)$, strain rate $(\dot{\varepsilon})$, austenite grain size $D$ and chemical composition of the steel according to [4]:

$$
t_{0.5}=A \mathcal{E}^{p} \mathcal{E}^{q} D^{s} \exp \left(\frac{Q}{R T}\right)
$$

where $Q$ is the activation energy, $R$ is the universal gas constant $\left(8.3145 \mathrm{Jmol}^{-1} \mathrm{~K}^{-1}\right)$ and $p, q, s$ and $A$ are constants.

The temperature limit between the stages of full recrystallization and beginning of recrystallization inhibition as a consequence of precipitation comes at a point known as "Static Recrystallization Critical Temperature” (SRCT) [4,5]. On the other hand, in a continuous-cooling multipass thermomechanical test, the temperature below which the recrystallization of austenite during the time between successive passes (called “interpass time”) starts to be incomplete is known as temperature of no-recrystallization $\left(T_{\mathrm{nr}}\right)[2]$.

It is known that austenite microstructure is affected by the hot rolling parameters employed (reheating temperature, strain applied per pass, interpass time, final rolling temperature, etc.) and that the microstructure of austenite just before cooling to room temperature has a major influence on the final ferrite-pearlite microstructure [6-9]. Therefore, one of the most important aspects to be studied during a certain multipass hot rolling schedule is the accurate assessment of the strengthening state of austenite and the quantification of the volume fraction of recrystallization during rolling at temperatures below $T_{\mathrm{nr}}$ and especially at the end of rolling, near phase transformation temperature $A_{\mathrm{r} 3}$. To carry out this characterization, metallographic studies can be used $[10,11]$, but metallography is a time-consuming and not always successful technique. 
Calculation methods such as the "anisothermal (non-isothermal) fractional softening” $[12,13]$ give an approximation of recrystallized fraction, but this technique includes the contribution of recovery to softening, which can be very high under certain deformation conditions and/or material characteristics [14]. Besides, it is sometimes necessary to know other empirical constitutive parameters or to make preliminary tests to approximate the yield stress of a fully recrystallized material $[13,15]$. On the other hand, mathematical models have also been developed and simulations have been carried out in order to evaluate the austenite recrystallization or softening kinetics and the resulting grain size during hot rolling of steels, i.e. under non-isothermal conditions [16-21].

Niobium is the microalloying element that most delays static recrystallization kinetics, even when it is in solution in the austenite [1,22]. In this work the evolution of static recrystallization of austenite is characterized in a Nb-microalloyed steel. Thermomechanical tests are carried out under isothermal and continuous cooling conditions and conclusions about the relationship between the results coming from both thermal paths are extracted. The influence of interpass time on recrystallization and grain size is assessed. An empirical method to estimate the recrystallized fraction during rolling from the stress-strain data obtained in the thermomechanical tests is presented and a comparison with the results of metallography and the technique of non-isothermal fractional softening is done.

\section{EXPERIMENTAL PROCEDURE}

The steel studied was manufactured by Electroslag Remelting (ESR) in a laboratory unit capable of producing $30 \mathrm{~kg}$ ingots. As Table 1 shows, the steel has $0.20 \% \mathrm{C}$ and $0.007 \% \mathrm{Nb}$. Double-deformation isothermal tests as well as multipass hot 
rolling simulation tests were carried out in a computer-controlled hot torsion machine, on specimens with a gauge length of $50 \mathrm{~mm}$ and a diameter of $6 \mathrm{~mm}$. Prior to the torsion tests the specimens were austenitized during $10 \mathrm{~min}$ at $1250{ }^{\circ} \mathrm{C}$, a temperature high enough to completely dissolve the Nb precipitates [23], as Table 2shows.

After reheating, the temperature was rapidly lowered to that corresponding to the first deformation pass in each test. In the isothermal double-deformation experiments, this temperature was maintained after deformation during a certain holding time, after which a longer second deformation was applied in order to calculate recrystallized fraction $\left(X_{a}\right)$. The value of $X_{a}$ was measured using the "back extrapolation" technique [24]. This method presents the advantage of determining the recrystallized fraction instead of the softened fraction, i.e. the effect of recovery is excluded from the double deformation data [10], so more accurate comparison with observed microstructures can be carried out. The back extrapolation method assumes that the second stress-strain curve in a double deformation test (Figure 1) coincides with the curve of a fully annealed steel after a certain time. Consequently, the first curve is superimposed onto the second deformation curve to fit both flow curves. The method estimates the recrystallized fraction as the ratio:

$$
X_{a}=\frac{\sigma_{m}-\sigma_{1}}{\sigma_{m}-\sigma_{0}}
$$

where $\sigma_{\mathrm{m}}$ is the maximum flow stress of the first $\sigma$ - $\varepsilon$ curve, $\sigma_{0}$ is the initial flow stress and the stress $\sigma_{1}$ results from the intersection of the extrapolated curve and the reloading line (see Fig. 1).

Several temperatures between $850{ }^{\circ} \mathrm{C}$ and $1100{ }^{\circ} \mathrm{C}$ and holding times between 
$0.5 \mathrm{~s}$ and $1000 \mathrm{~s}$ were used in order to build the curves of recrystallized volume fraction against time $\left(X_{\mathrm{a}}(\mathrm{t})\right)$ as well as the Recrystallization-Precipitation-Time-Temperature (RPTT) diagram [25-27], where the interaction between these two processes is clearly observed. The equivalent strain $(\varepsilon)$ applied in the first pass was 0.35 , lower than the critical strain which leads to the start of dynamic recrystallization. The strain rate $(\dot{\varepsilon})$ was kept constant at a value of $3.63 \mathrm{~s}^{-1}$.

In some samples the second deformation after holding time was replaced by a water-quench and subsequent metallographic preparation. Microstructure was observed in optical microscope to verify the accuracy of back extrapolation method in determining the recrystallized fraction. All the microstructural studies carried out in this study were done observing more than 20 fields on a longitudinal surface of the specimens at $2.65 \mathrm{~mm}$ from the axis. To reveal the prior austenite grain boundaries, the samples were etched with an aqueous solution of saturated picric acid mixed with a wetting agent. Some droplets of hydrochloric acid were added just before etching to activate the solution.

In the hot rolling simulation tests, the temperature of the first pass was equal to $1150{ }^{\circ} \mathrm{C}$. The simulations consisted of 20 passes made under continuous cooling conditions, with a temperature step of $25{ }^{\circ} \mathrm{C}$ between passes, the last pass being carried out at $675{ }^{\circ} \mathrm{C}$. The interpass time $(\Delta \mathrm{t})$ took two different values equal to $20 \mathrm{~s}$ and $200 \mathrm{~s}$. The strain and strain rate applied in each pass were the same as those used in isothermal tests $\left(\varepsilon=0.35, \dot{\varepsilon}=3.63 \mathrm{~s}^{-1}\right)$. After determining the critical hot rolling temperatures $\left(T_{\mathrm{nr}}\right.$, $\left.A_{\mathrm{r} 3}, A_{\mathrm{r} 1}\right)$, supplementary quench-interrupted tests were carried out in order to evaluate the evolution of microstructure (grain size, recrystallization) during rolling. In these tests, samples were deformed following the same schedule until they suffered a last deformation step. Then, the temperature was lowered $25{ }^{\circ} \mathrm{C}$ during the corresponding $\Delta \mathrm{t}$ 
to reach the quenching temperature, so microstructure just before the application of the rolling pass was evaluated. The austenite grain size $(D \gamma)$ and aspect ratio were determined by means of the linear intersection technique. Recrystallized fraction was measured using standard point-counting metallographic technique.

\section{RESULTS}

\subsection{Double deformation isothermal tests and multipass hot rolling simulations}

First of all, the initial austenite grain size after reheating was determined. As shown in Table 2, the steel studied had a grain size of $140 \mu \mathrm{m}$ after $10 \mathrm{~min}$ at $1250{ }^{\circ} \mathrm{C}$. The torsion test gives the values of torque applied versus the number of turns made on the specimen, which are transformed respectively into equivalent stress and strain using Von Mises criterion [28]. Figure 2a shows the relationship between recrystallized fraction $\left(X_{a}\right)$ and time. At high temperatures $\left(1100{ }^{\circ} \mathrm{C}, 1000^{\circ} \mathrm{C}\right)$ the recrystallization progresses continuously following an Avrami's law until completion. However, at lower temperatures a plateau is formed, indicating a period of time where the recrystallization is temporarily inhibited by the pinning forces exerted by $\mathrm{Nb}$ precipitates. After the plateau, the recrystallization progresses again until it is complete, following a similar trend to that recorded before the plateau.

Curves of Fig. 2a have been used to deduce the temperatures and times corresponding to different recrystallized fractions, as well as the induced precipitation start $\left(P_{\mathrm{s}}\right)$ and finish $\left(P_{\mathrm{f}}\right)$ times, given by the times of the beginning and the end of the plateaus of inhibition of recrystallization [3]. In this way, the RPTT diagram of Figure

$\mathbf{2 b}$ has been drawn. The horizontal asymptote of the $P_{\mathrm{s}}$ and $P_{\mathrm{f}}$ curves is the Static Recrystallization Critical Temperature (SRCT) [4,5]. 
Figure 3a shows the stress-strain curves of the 20 hot rolling passes simulated. At first deformations, stress raises as temperature decreases, after which there is a change in the slope with a growth in the stress that means a greater tendency to strengthening. The meaning of this figure is better explained by observing Figure $\mathbf{3 b}$, which shows the graphic representation of mean flow stress (MFS) versus the inverse of the absolute temperature. MFS is determined in each step by dividing the area below the stress-strain curve by the strain applied. In Fig. $\mathbf{3 b}$ it is possible to see four different zones. In the first zone (phase I), which corresponds to deformations at high temperatures, MFS grows as temperature decreases. Austenite recrystallizes completely between passes and the increase in stress is due only to the decrease in temperature. In the second zone of the curve (phase II) there is a change in the slope, which indicates a greater tendency towards hardening. Here the stress accumulates in the austenite, whose recrystallization between passes is partially inhibited. The third phase (III), characterized by a drop in MFS as temperature decreases, corresponds to the austenite $\rightarrow$ ferrite partial transformation. In this region the formation of ferrite, which is a softer phase, causes a descent in the stress values. In the fourth and final region (IV), where the stress rises again as the temperature drops, the ferrite formation finishes and the eutectoid transformation takes place [2].

The intersection of the straight regression lines of phases I and II defines the value of $T_{\mathrm{nr}}$ and the intersection of the regression lines of phases II and III determines the value of $A_{\mathrm{r} 3}$ [2]. The value of eutectoid transformation temperature $\left(A_{\mathrm{r} 1}\right)$ is placed at a point close to the minimum of the parabola corresponding to phases III and IV [2,29]. The increase of stress at lower temperatures indicates the cooling of ferrite-pearlite microstructure. Figures $\mathbf{3 c}$ and $\mathbf{3 d}$ show respectively the stress-strain curves and the MFS-(1/T) plot for a hot rolling simulation where $\Delta t=200 \mathrm{~s}$. It can be seen that the 
longer time between passes permits a complete static recrystallization until very low temperatures, as $T_{\mathrm{nr}}=753^{\circ} \mathrm{C}$.

The magnitude known as "accumulated stress" $(\Delta \sigma)[29]$ will be given by the length of the vertical segment drawn between the straight regression lines of phases I and II, as illustrated in Fig. 3b. The value of $\Delta \sigma$ informs about the progressive strengthening of austenite during rolling at temperatures below $T_{\mathrm{nr}}$. Figure $\mathbf{4}$ shows the evolution of accumulated stress during the two simulated hot rolling schedules. $\Delta \sigma$ is zero at $\mathrm{T}=T_{\mathrm{nr}}$ and grows during phase II to reach its maximum value at $A_{\mathrm{r} 3}$ [29]. The value of $\Delta \sigma$ at $A_{\mathrm{r} 3}$ is higher for the test with $\Delta \mathrm{t}=20 \mathrm{~s}$, which means that the austenite has reached the end of hot rolling with a more strengthened microstructure. Consequently, a finer ferrite grain size after cooling can be expected for the test with shorter $\Delta \mathrm{t}[6,30,31]$. On the other hand, the austenite reaches the last deformation steps with a less strengthened structure when $\Delta \mathrm{t}=200 \mathrm{~s}$. Therefore, the value of MFS near $A_{\mathrm{r} 3}$ is lower, so the drop in stress due to ferrite formation (at temperatures below $A_{\mathrm{r} 3}$ ) will be harder to detect than for the case with $\Delta \mathrm{t}=20 \mathrm{~s}$ and indeed it cannot be noticed in Fig. 3d. In this case just a slight change in the slope is observed and accurate determination of $A_{\mathrm{r} 1}$ temperature has not been possible.

\subsection{Microstructural evolution of austenite during hot rolling}

The pictures of Figure 5 illustrate the microstructural evolution of austenite during the hot rolling schedule shown in Figs $\mathbf{3 a}$ and $\mathbf{3 b}$. During the first passes, the initial austenite grain size $(140 \mu \mathrm{m})$ is considerably refined as a result of successive recrystallizations. After 8 passes, at $950{ }^{\circ} \mathrm{C}$, i.e. a temperature slightly above $T_{\mathrm{nr}}(924$ ${ }^{\circ} \mathrm{C}$ ) grains are rather equiaxed. After two more deformations and a temperature decrease of $50{ }^{\circ} \mathrm{C}\left(\mathrm{T}=900^{\circ} \mathrm{C}\right.$, just below $\left.T_{\mathrm{nr}}\right)$, some unrecrystallized grains that are coarser and 
more elongated than the average start to appear. At the end of rolling $\left(\mathrm{T}=775^{\circ} \mathrm{C}\right)$ the austenite has suffered several deformations in the "no-recrystallization" temperature range, but there has also been time to reach a certain degree of recrystallization during successive interpass times. Thus the final microstructure consists of a mixture of elongated unrecrystallized grains and very fine equiaxial recrystallized grains. On the other hand, Figure 6 demonstrates that austenite can recrystallize completely between passes until lower temperatures when $\Delta \mathrm{t}=200 \mathrm{~s}$. Besides, recrystallized grains can eventually grow so observed grain size is coarser than in Fig. 5.

In Figure 7a it can be seen that remarkable austenite grain refinement occurs in the first rolling passes, before reaching no-recrystallization temperature, as a result of successive recrystallizations. With $\Delta \mathrm{t}=20 \mathrm{~s}$, austenite grain size at $\mathrm{T}=T_{\mathrm{nr}}$ is close to 20 $\mu \mathrm{m}$, which does not greatly differ from the values found by other authors [32] for Ti steels with two different Ti contents and initial grain sizes and similar deformation conditions. The substantial grain refinement occurred in the first rolling passes makes the grain size at $\mathrm{T}=T_{\mathrm{nr}}$ to be practically independent on the initial microstructure after reheating [32,33]. As shown in Fig. 6, when $\Delta t=200 \mathrm{~s}$ the austenite grain size measured during rolling is coarser. Once the recrystallization of austenite is complete, this long time has allowed recrystallized grain to grow until next deformation is applied. Below $T_{\mathrm{nr}}$, and especially in the last passes, $\Delta \mathrm{t}=20 \mathrm{~s}$ is not long enough for the complete recrystallization of austenite. Pinning forces exerted by precipitates take comparable or even higher values than the driving forces for recrystallization $[34,35]$ and grains elongate progressively. This can be verified in Fig. 7b by evaluating the austenite grain aspect ratio [34], which represents the ratio between the number of grains detected per unit length in deformation direction and its perpendicular. In this case, the directions perpendicular and parallel to the axis of torsion sample have been 
respectively taken. Fig. 7b shows that the growth of aspect ratio with the temperature drop is evident at temperatures near $T_{\mathrm{nr}}$ when $\Delta \mathrm{t}=20 \mathrm{~s}$, and the average value of aspect ratio at $\mathrm{T}=T_{\mathrm{nr}}$ is about 1.1 . In the case of the longest $\Delta \mathrm{t}$, aspect ratio is practically constant and equal to 1 in the two temperatures studied because there is complete static recrystallization until very low temperatures.

\subsection{Approximation of recrystallized fraction during hot rolling}

A method to estimate the volume fraction of static recrystallization during hot rolling without carrying out metallographic studies of quenched samples was designed. This method could be useful in cases where experimental measurement of $X_{\mathrm{a}}$ by observation of quenched samples is difficult. The first step of this method consists of the application of back extrapolation technique on pairs of stress-strain $(\sigma-\varepsilon)$ curves corresponding to consecutive hot rolling passes (Figs. 3a and 3c). An “apparent” value of recrystallized fraction $\left(X_{\mathrm{a}}\right)$ is obtained. This value is affected by the temperature drop between passes, i.e. it reflects the hardening of the steel derived from cooling that can be seen in phase I of Fig. 3b. At temperatures above $T_{\mathrm{nr}}$, the value of $X_{\mathrm{a}}$ is always lower than 1 and it is practically constant and close to 0.9 (90\%). In line with the classical definition of $T_{\mathrm{nr}}$ and also according to the results of the microstructural studies carried out on quenched samples (Figs. 5, 6 and 7b), the static recrystallization of austenite can be assumed to be complete at temperatures above $T_{\mathrm{nr}}$. To subtract the effect of temperature on austenite strength this hypothesis was adopted. Therefore, the value of $X_{\mathrm{a}}$ in each pass was "normalized", i.e. it was divided by the average of the values of $X_{\mathrm{a}}$ at temperatures above $T_{\mathrm{nr}}\left(\bar{X}_{\mathrm{a}}\right)$. In this way, the new value of $X_{\mathrm{a}}\left(X_{\mathrm{a}}{ }^{\prime}\right)$ will be approximately equal to 1 between the first pass and $\mathrm{T}=T_{\mathrm{nr}}$. Finally, it should be taken into account that the values of $X_{\mathrm{a}}$ and $X_{\mathrm{a}}$ ' inform about the austenite recrystallization 
during a single interpass (i.e. between the $i$ th and $(i+1)$ th passes) but they do not reflect the progressive accumulation of strengthening in an average mixed microstructure compared to the fully recrystallized material existing at temperatures above $T_{\mathrm{nr}}$. For example, if the calculated recrystallized fraction after three consecutive passes is respectively equal to $100,90 \%$ and $80 \%$, the "accumulated" recrystallized fraction after the third interpass time $\left(X_{\mathrm{a}}{ }^{*}\right)$ would not be $80 \%$ but it should be the result of multiplying the successive recrystallized fractions: $100 \% \cdot 90 \% \cdot 80 \%=72 \%$. The mathematical expressions would be summarized as:

$X_{a}^{i}=$ Result of Back Extrapolation method applied on curves of passes (i-1) and $i$;

$\overline{X_{a}}=\frac{\sum_{i=2}^{n} X_{a}^{i}}{n-1} ; \quad n=$ number of pass where $\left(T \approx T_{n r}\right)$;

$\left(X_{a}^{i}\right)^{\prime}=\frac{X_{a}^{i}}{X_{a}}$

$X_{a}^{i} *=\left(X_{a}^{i}\right)^{\prime} X_{a}^{i-1} *$

It should be taken into account that the value of $\overline{X_{a}}$ should be really the number that makes the average of $X_{\mathrm{a}}{ }^{*}$ between the first pass and $T_{\mathrm{nr}}$ (and not the average of $X_{\mathrm{a}}$ ') to be close to 1 . Then, equation (5) should be replaced by the condition:

$$
\overline{X_{a}} \Rightarrow \frac{\sum_{i=2}^{n} X_{a}^{i} *}{n-1}=\frac{\sum_{i=2}^{n} \frac{X_{a}^{i}}{X_{a}} X_{a}^{i-1} *}{n-1}=1 ; \quad n=\text { number of pass where }\left(T \approx T_{n r}\right)
$$

The values of $X_{\mathrm{a}} *$ depend on $\overline{X_{a}}$, so a numeric resolution process is necessary to 
make this minor correction in order to calculate $\overline{X_{a}}, X_{\mathrm{a}}$ ' and $X_{\mathrm{a}}{ }^{*}$ more accurately.

Figure 8 shows the application of this method to calculate $X_{\mathrm{a}}{ }^{*}$ using the $\sigma-\varepsilon$ plots of Fig. 3a and 3c. In agreement with the initial hypotheses, recrystallized fraction $X_{\mathrm{a}}{ }^{*}$ is almost constant and close to 1 until $T_{\mathrm{nr}}$ is attained. Below this temperature, $X_{\mathrm{a}}{ }^{*}$ starts to decrease and austenite accumulates a strengthening. The calculated values of $X_{\mathrm{a}}{ }^{*}$ have been compared to those measured by quantitative metallography $\left(X_{\mathrm{am}}\right)$ on microstructures of quenched samples like those shown in Fig. $\mathbf{5}$ and 6. Calculated and observed recrystallized fraction are very similar so it can be concluded that the method designed is adequate and reflects with reasonable accuracy the evolution of recrystallization during hot rolling.

From the stress-strain curves obtained in multipass torsion tests (Fig. 3a and 3c) it was also possible to determine the values of the "fractional softening" that takes place between passes. The non-isothermal fractional softening (FS) was calculated by means of the following expression $[12,32,33,36]$ :

$$
F S(\%)=\frac{\sigma_{m}^{i}-\sigma_{y}^{i+1} \frac{\sigma_{0}^{i}}{\sigma_{0}^{i+1}}}{\sigma_{m}^{i}-\sigma_{0}^{i}} \times 100
$$

where $\sigma_{m}^{i}$ and $\sigma_{y}^{i+1}$ are the maximum and the yield stresses for both, the ith (at temperature $T_{\mathrm{i}}$ ) and $(i+1)$ th (at temperature $T_{\mathrm{i}+1}$ ) passes, respectively. $\sigma_{0}^{i}$ and $\sigma_{0}^{i+1}$ are the yield stresses of a fully recrystallized material for the $i$ th and $(i+1)$ th passes. The yield stresses were determined by the $2 \%$ offset method. $\sigma_{m}^{i}$ and $\sigma_{y}^{i+1}$ are based on the pass-to-pass flow curves of Figs. 3a and 3c. $\sigma_{0}^{i}$ and $\sigma_{0}^{i+1}$ are determined from the linear 
relationship derived from the values of yield stresses $\left(\sigma_{y}\right)$ measured in the stress-strain curves like those of Figs. 3a and 3c corresponding to the temperature range of complete recrystallization $\left(\mathrm{T}>T_{\mathrm{nr}}\right)$.

The values of $F S$ for both interpass times are also represented against temperature in Fig. 8. It can be seen that the value of non-isothermal fractional softening at temperatures above or close to $T_{\mathrm{nr}}$ properly eliminates the influence of temperature on stress, so the values of FS are close to the calculated recrystallized fraction $X_{\mathrm{a}}{ }^{*}$ and the value of $X_{\mathrm{am}}$ measured by optical microscopy (i.e. near 100\%). However, at lower temperatures, mixed (i.e. partially recrystallized) microstructures appear. As mentioned above, the "back extrapolation" method suppresses the recovered fraction from the total softened fraction, so it yields lower values than the doubledeformation method used to calculate FS. The fraction of recovery can be remarkably high for short interpass times or low temperatures, i.e. when the degree of recrystallization is lower [14,37]. Besides, the "non-isothermal fractional softening" method does not seem to consider accurately the accumulation of successive partial recrystallizations at temperatures lower than $T_{\mathrm{nr}}$ that is expressed in equation (7). As a result, the values of $F S$ start to deviate from $X_{\mathrm{a}}{ }^{*}$ at lower temperatures and at the end of hot rolling, near $A_{\mathrm{r} 3}$, the values of $F S$ are $20-25 \%$ higher than calculated $X_{\mathrm{a}}{ }^{*}$ and $X_{\mathrm{am}}$ measured by metallography.

It can be seen that the values of $X_{\mathrm{a}}{ }^{*}$ and FS are higher than 1 in some passes at $\mathrm{T}>T_{\mathrm{nr}}$. This can be attributed to the softening caused by the recrystallized grain coarsening at high temperatures, where the pinning forces exerted by Nb precipitates are not capable of completely counteract the advance of austenite grain boundaries once recrystallization is achieved. This is more evident in Fig. 8b, where there is a longer interpass time to allow grain growth. It is also interesting to note that in both cases 
studied the percentage of recrystallization when $T_{\mathrm{nr}}$ is reached is not exactly $100 \%$, but about $90 \%$. It is obvious that the accuracy in the determination of $T_{\mathrm{nr}}$ is limited by the temperature step of $25{ }^{\circ} \mathrm{C}$ in multipass hot torsion tests. Besides, the method to determine $T_{\mathrm{nr}}$ through the increase in MFS will always need an appreciable degree of hardening that can easily correspond to $10 \%$ of unrecrystallized fraction. Furthermore, the presence of particles at temperatures below the precipitation start will affect to some extent the values of yield, maximum and mean flow stress and consequently the results of these techniques.

In fact, the back extrapolation method employed to estimate the recrystallized fraction during isothermal and multi-pass non-isothermal conditions makes use of stress values that can be affected by the intrinsic strengthening effect of precipitates, so it could be expected that certain inaccuracy is introduced in the calculation once the precipitation starts. It has been proposed that the precipitates formed during hot working or heat treatment in austenite are rather coarse (around $20 \mathrm{~nm}$ in diameter) and thus they have only a limited effect for precipitation hardening compared to the precipitation strengthening effect caused in ferrite by the very fine particles formed during cooling [38]. Nevertheless, it is known that fine particles can hinder the climb of dislocations that governs the plastic flow of the austenite and can contribute in that way to strengthen the austenite [39]. The hardening effect of precipitates can be seen for example in the points of Fig. 2a where $X_{\mathrm{a}}$ takes a value under the horizontal plateau. Some authors represent this effect as a "hump" in the softening curve [40,41]. Then, Fig. 2a shows that the result of the calculation method is influenced by particle hardening. However, it should be taken into account that the decrease in the calculated value of $X_{\mathrm{a}}$ associated to precipitation is temporary and it is rarely higher than $10 \%$ $[4,40,41]$. Besides, the method proposed for non-isothermal conditions uses consecutive 
pairs of $\sigma-\varepsilon$ curves. Therefore, if the hypothetical case where the onset of precipitation occurs just after the first $\sigma-\varepsilon$ curve is considered, the increase in "yield stress" of the second curve ( $\sigma_{1}$ of Eq. (1)) caused by precipitates will be translated into a higher maximum stress $\left(\sigma_{\mathrm{m}}\right)$ of the first curve in the following pair of curves. Consequently, it could be assumed that the hardening effect is lessened or compensated at lower temperatures and the possible error is limited. On the other hand, the low amount of $\mathrm{Nb}$ in the steel studied $(0.007 \% \mathrm{Nb})$ is able to inhibit the recrystallization temporarily (Fig. 2a), which means that the start of the inhibition of recrystallization in isothermal double deformation conditions should practically coincide with the onset of precipitation, as confirmed by Kang et al [40]. This denotes that the detection of the point where recrystallization starts to be incomplete as a result of strain induced precipitation during multipass tests $\left(X_{\mathrm{a}}^{*}<1\right)$ will be significantly accurate.

On the other hand, several authors have previously shown that $T_{\mathrm{nr}}$ does not necessarily correspond to the exact transition from complete to partial recrystallization and, depending on $\Delta \mathrm{t}$ and pass strain, there can be a certain amount of unrecrystallized austenite after the pass immediately before $T_{\mathrm{nr}}[5,32,33,36]$. Some authors define the lowest temperature above which recrystallization between passes is complete (i.e. higher than 85-95\%) as the "recrystallization limit temperature” (RLT) [42]. The "recrystallization stop temperature” (RST) would be the highest temperature at which recrystallization is completely absent (i.e. less than 5\%) [42]. Radovic et al. [36] approximated the $F S$ versus $(1 / \mathrm{T})$ plots by three linear segments, which intersect at two temperatures that can be assimilated to RLT and RST. These authors found that $T_{\mathrm{nr}}$ correlates well with RLT, but Abad et al [33] affirm that $T_{\mathrm{nr}}$ values are located between RLT and RST. Figure 9 shows that RLT is close to $T_{\mathrm{nr}}$ in both experiments. This agrees with the initial hypothesis that locates $T_{\mathrm{nr}}$ in the point where deviation from the linear 
hardening behavior with the decrease of temperature is found in the MFS plots of Figs.

3b and 3d. The second change in slope that determines RST cannot be located in Fig. 9, probably because $X_{\mathrm{a}}$ * is higher than $20 \%$ even at low temperatures close to $A_{\mathrm{r} 3}$. For example, Figure 5 shows that very small, equiaxed recrystallized grains can be found in the sample deformed at $800{ }^{\circ} \mathrm{C}$ and quenched from $775^{\circ} \mathrm{C}$. This means that although the austenite has suffered several deformations in the "no-recrystallization” temperature range, a certain fraction of recrystallization during the interpass time of $20 \mathrm{~s}$ is still possible at those low temperatures.

On the other hand, the comparison of Fig. 4 and Figs. 5-9 leads to the conclusion that the increasing value of $\Delta \sigma$ as long as samples are cooled is an accurate qualitative indication of the progressive strengthening of austenite below $T_{\mathrm{nr}}$ [29]. Besides, comparing the results for both interpass times, the quantitative relationship between a higher value of $\Delta \sigma$ and a lower degree of static recrystallization of austenite is verified.

\subsection{Effect of successive hot rolling passes. Comparison between SRCT and $T_{n r}$}

Comparison of $T_{\mathrm{nr}}$ and SRCT is not easy, as both parameters represent the start of inhibition of recrystallization but they do not have the same definition [5]. SRCT is determined by isothermal tests and is independent of the time, whereas $T_{\mathrm{nr}}$ is determined by means of continuous cooling rolling simulations and depends on $\Delta \mathrm{t}$. $T_{\mathrm{nr}}$ presents a value lower than SRCT in the steel studied for both interpass times applied. According to theory, the value of $T_{\mathrm{nr}}$ in microalloyed steels would be higher than SRCT for shorter interpass times and would pass through a minimum, which occurs at $\Delta \mathrm{t}=10-15 \mathrm{~s}$. This interval reflects the solute drag effect of alloying elements [43]. For medium times, $T_{\mathrm{nr}}$ raises with increasing $\Delta \mathrm{t}$ because of the higher volume fraction of fine precipitates that exert a strong pinning effect. Finally, for $\Delta \mathrm{t}$ longer than $50 \mathrm{~s}, T_{\mathrm{nr}}$ decreases again as a 
consequence of particle coarsening [36,43].

Fig. 2a indicates that the value of static recrystallization at $950{ }^{\circ} \mathrm{C}$ when isothermal holding time after deformation is $20 \mathrm{~s}$ is approximately equal to $65 \%$. However, Fig. $3 \mathbf{b}$ shows that austenite presents complete recrystallization at $950^{\circ} \mathrm{C}$ with $\Delta \mathrm{t}=20 \mathrm{~s}$ (ninth point of the curve, $\mathrm{T}>T_{\mathrm{nr}}$ ). This can be also verified observing the microstructure in Fig. 5 and the value of $X_{a}^{*} \approx 100 \%$ in Fig. 8a. As seen in Fig. 7a, the application of successive rolling passes (especially at temperatures above $T_{\mathrm{nr}}$ ) provokes an austenite grain refinement. As equation (2) shows, this refinement accelerates recrystallization kinetics. When grain is refined, the area of austenite grain boundaries (potential nucleation sites) increases. Besides, a reduction in grain size can contribute together with strain applied to augment the stored energy due to deformation [44]. Consequently, the curves of recrystallized fraction against time are shifted to shorter times. Thus, a steel that is being deformed at temperatures below SRCT can pass the stage of inhibition of recrystallization by induced precipitation delimited by the plateaus in Fig. 2a and reach complete recrystallization in a much shorter time than the indicated in $X_{\mathrm{a}}(\mathrm{t})$ curves. In this case, the strain induced precipitation could be expected to happen after rolling passes applied at temperatures above $T_{\mathrm{nr}}$, as grain refinement also accelerates precipitation [45].

\section{CONCLUSIONS}

- By means of thermomechanical tests, metallographic studies and analysis of grain aspect ratio carried out in a Nb-microalloyed steel, it has been verified that, for the deformation conditions used, no-recrystallization temperature $\left(T_{\mathrm{nr}}\right)$ approximately corresponds to the temperature where recrystallization starts to be incomplete during 
rolling.

- The fraction of austenite static recrystallization during hot rolling $\left(X_{\mathrm{a}}{ }^{*}\right)$ can be estimated by means of a calculation method that only needs the stress-strain data of thermomechanical tests. Comparison with metallographic studies verifies the remarkable accuracy of this method.

- The value of non-isothermal fractional softening $(F S)$ is close to the recrystallized fraction at temperatures above or close to $T_{\mathrm{nr}}$. However, at lower temperatures, this parameter overestimates the value of austenite recrystallization during hot rolling because it includes the percentage of recovery and does not properly consider the accumulation of strengthening between successive passes. Consequently, the value of FS at temperatures near $A_{\mathrm{r} 3}$ could be more than 20\% higher than $X_{\mathrm{a}}{ }^{*}$.

- The value of $T_{\text {nr }}$ obtained in mean flow stress (MFS) vs. (1/T) plots is close to the value of recrystallization limit temperature (RLT) measured in FS-(1/T) plots.

- A longer interpass time permits complete static recrystallization until lower temperatures. Consequently, $T_{\mathrm{nr}}$ value decreases and recrystallized grain coarsening can occur at $\mathrm{T}>T_{\mathrm{nr}}$.

- Accumulated stress measured in the MFS plots represents a suitable assessment of the progressive strengthening of austenite below $T_{\mathrm{nr}}$.

- A remarkable austenite grain refinement is achieved in the first hot rolling passes after reheating, i.e. at temperatures much higher than $T_{\mathrm{nr}}$.

- The effect of grain size on recrystallization and precipitation kinetics and their mutual interaction helps to explain the discrepancy in the value of recrystallized fraction determined at the same temperature on isothermal double-deformation tests and continuous-cooling multipass hot rolling simulations. 


\section{REFERENCES}

[1] C.M. Sellars, Proc. Int. Conf. on Hot Working and Forming Processes (eds. C.M. Sellars and C.J. Davies), p. 3, The Metal Society of London (1980).

[2] F.H. Samuel, S. Yue, J.J. Jonas and B.A. Zbinden, ISIJ Int. 29, 878 (1989).

[3] S. F. Medina, A. Quispe, P. Valles and J. L. Baños, ISIJ Int. 39913 (1999).

[4] S. F. Medina, A. Quispe and M. Gomez, Mater. Sci. Tech-Lond. 17536 (2001).

[5] S. F. Medina, Mater. Sci. Tech-Lond. 14217 (1998).

[6] B. Engl and K. Kaup, Proceedings of the International Conference on Thermomechanical Processing of Microalloyed Austenite (eds. A. J. DeArdo, G.

A. Ratz and P. J. Wray), p. 467, TMS AIME, Pittsburgh, PA, (1982).

[7] M. Umemoto, A. Hiramatsu, A. Moriya, T. Watanabe, S. Nanba, N. Nakajima and G. Anan, Y. Higo, ISIJ Int. 32, 306 (1992).

[8] P. Korczak, H. Dyja and J. W. Pilarczyk, Met. Mater.-Int. 4, 707 (1998)

[9] M. Jahazi, Met. Mater.-Int. 4, 818 (1998)

[10] J.S. Perttula and L.P. Karjalainen, Mater. Sci. Tech-Lond. 14, 626 (1998).

[11] A.I. Fernandez, B. Lopez, and J.M. Rodriguez-Ibabe, Scripta Mater. 40, 543 (1999).

[12] W.J. Liu and M.G. Akben, Can. Metall. Q. 26, 145 (1987).

[13] A. Streisselberger, R. Kaspar and O. Pawelski, Metall. Trans. A 16, 67 (1985).

[14] E.J. Giordani, A.M. Jorge, Jr. and O. Balancin, Scripta Mater 55, 743 (2006).

[15] N.D. Ryan and H.J. McQueen, J. Mater. Process. Tech. 36, 103 (1993).

[16] D. Y. Kim and J. J. Park, Met. Mater.-Int. 4, 760 (1998)

[17] Y. Lee, S. Choi, S. J. Yoo, W. Y. Choo, Met. Mater.-Int. 6, 267 (2000)

[18] Y. Lee, S. I. Kim , S. Choi , B. L. Jang, W. Y. Choo, Met. Mater.-Int. 7, 519 
(2001)

[19] S. W. Choi , Y. S. Lee, Met. Mater.-Int. 8, 15 (2002)

[20] J.J. Jonas and E.I. Poliak, Mater. Sci. Forum 500-501, 15 (2005).

[21] S. Serajzadeh, Mater. Sci. Eng. A 448, 146 (2007).

[22] L. P. Karjalainen, T. M. Maccagno and J. J. Jonas, ISIJ Int. 35, 1523 (1995).

[23] E. T. Turkdogan, Iron Steelmaker 16, 61 (1989).

[24] H. L. Andrade, M. G. Akben and J. J. Jonas, Metall. Trans. A 14, 1967 (1983).

[25] S. F. Medina, A. Quispe and M. Gomez, Mater. Sci. Tech-Lond. 19, 99 (2003).

[26] K. J. Lee, Scripta Mater. 40, 837 (1999).

[27] H. S. Zurob, Y. Brechet and G. Purdy, Acta Mater. 49, 4183 (2001).

[28] A. Faessel, Rev. Métall. Cah. Inf. Tech. 33, 875 (1976).

[29] M. Gomez, O. Hernanz, S. F. Medina and P. Tarin, Steel Res. 73, 446 (2002).

[30] M.I. Vega, S.F. Medina, A. Quispe, M. Gomez and P.P. Gomez, Mater. Sci. Eng. A 423, 253 (2006).

[31] S. F. Medina, L. Rancel and M. Gomez, ISIJ Int. 48, 1263 (2008).

[32] M. Arribas, B. Lopez and J.M. Rodriguez-Ibabe, Mater. Sci. Eng. A 485, 383 (2008).

[33] R. Abad, A. I. Fernández, B. Lopez and J. M. Rodriguez-Ibabe, ISIJ Int. 41, 1373 (2001).

[34] E. J. Palmiere, C. I. Garcia and A. J. Deardo, Metall. Mater. Trans. A 27, 951 (1996).

[35] M. Gomez, S. F. Medina and P. Valles, ISIJ Int. 45, 1711 (2005).

[36] N. Radovic, D. Drobnjak, ISIJ Int. 39, 575 (1999).

[37] C. Devadas, I. V. Samarasekera and E. B. Hawbolt, Metall. Trans.A 22, 335 (1991). 
[38] K. Hulka, Niobium Information, CBMM 17/98 (1998).

[39] S. F. Medina, M. I. Vega, M. Gomez and P.P. Gomez, ISIJ Int. 45, 1307 (2005).

[40] K.B. Kang, O. Kwon, W.B. Lee and C.G. Park, Scripta Mater. 36, 1303 (1997).

[41] H. S. Zurob, C. R. Hutchinson, Y. Brechet and G. Purdy, Acta Mater. 50, 3075 (2002).

[42] B. Dutta and C. M. Sellars, Mater. Sci. Tech-Lond. 3, 197 (1987).

[43] D. Q. Bai, S. Yue, W. P. Sun and J. J. Jonas, Metall. Trans A 24, 2151 (1993).

[44] M. Kazeminezhad, Mater. Sci. Eng. A 486, 202 (2008).

[45] A. Quispe, S. F. Medina, M. Gomez and J. I. Chaves, Mater. Sci. Eng A 447, 11 (2007). 
Table 1. Chemical composition of the steel studied (weight \%).

\begin{tabular}{|c|c|c|c|c|c|c|c|c|}
\hline $\mathrm{C}$ & $\mathrm{Si}$ & $\mathrm{Mn}$ & $\mathrm{P}$ & $\mathrm{S}$ & $\mathrm{Al}$ & $\mathrm{Nb}$ & $\mathrm{N}$ & $\mathrm{O}$ \\
\hline 0.20 & 0.20 & 1.00 & 0.024 & 0.013 & 0.006 & 0.007 & 0.0056 & 0.0057 \\
\hline
\end{tabular}


Table 2. Calculated solubility temperatures of the steel studied [23]. Reheating temperature (reheating time $=10 \mathrm{~min}$ ) and measured austenite grain size $\left(D_{\gamma}\right)$ at reheating temperature.

\begin{tabular}{|c|c|c|c|c|}
\hline \multicolumn{2}{|c|}{ Solubility temperatures $\left({ }^{\circ} \mathrm{C}\right)$} & Reheating & \multirow{2}{*}{$D_{\gamma}(\mu \mathrm{m})$} \\
\cline { 1 - 2 } $\mathrm{NbC}_{0.7} \mathrm{~N}_{0.2}$ & $\mathrm{NbN}$ & $\mathrm{NbC}_{0.87}$ & temperature $\left({ }^{\circ} \mathrm{C}\right)$ & \\
\hline 1037 & 965 & 987 & 1250 & 140 \\
\hline
\end{tabular}




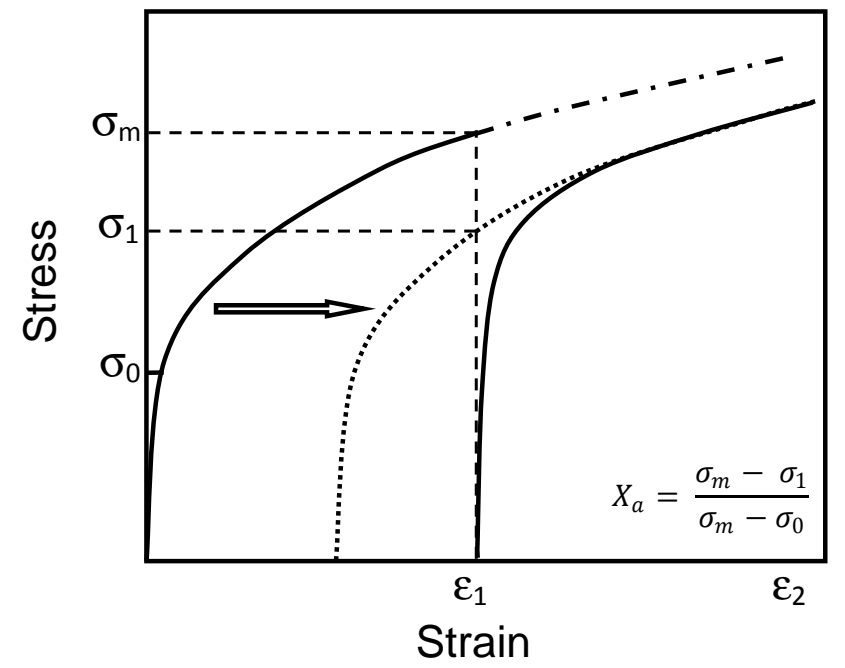

Fig. 1. Back extrapolation method used to estimate the recrystallized fraction. 


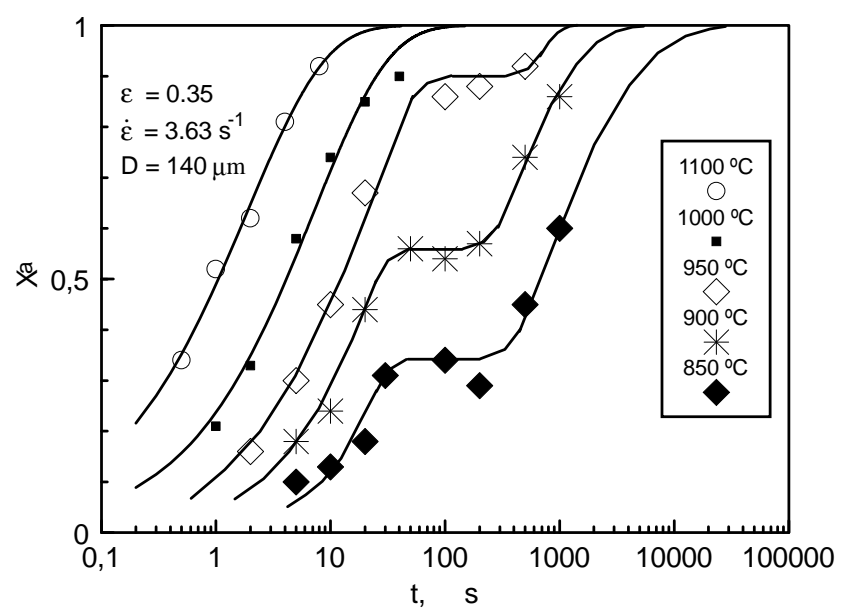

a)

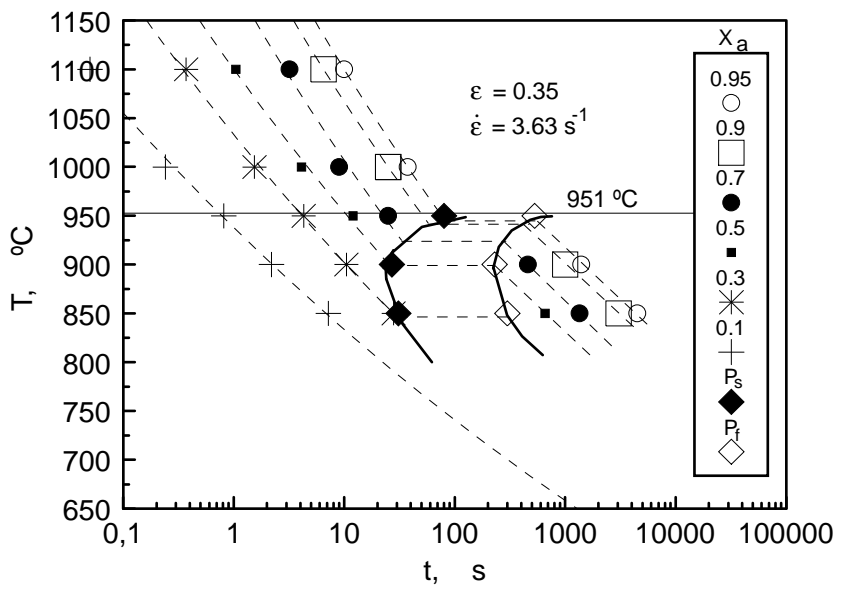

b)

Fig. 2. Double deformation isothermal test, $\varepsilon=0.35 ; \dot{\varepsilon}=3.63 \mathrm{~s}^{-1}$. a) Volume fraction of static recrystallization $\left(X_{\mathrm{a}}\right)$ versus holding time after deformation; b) RPTT diagram. 


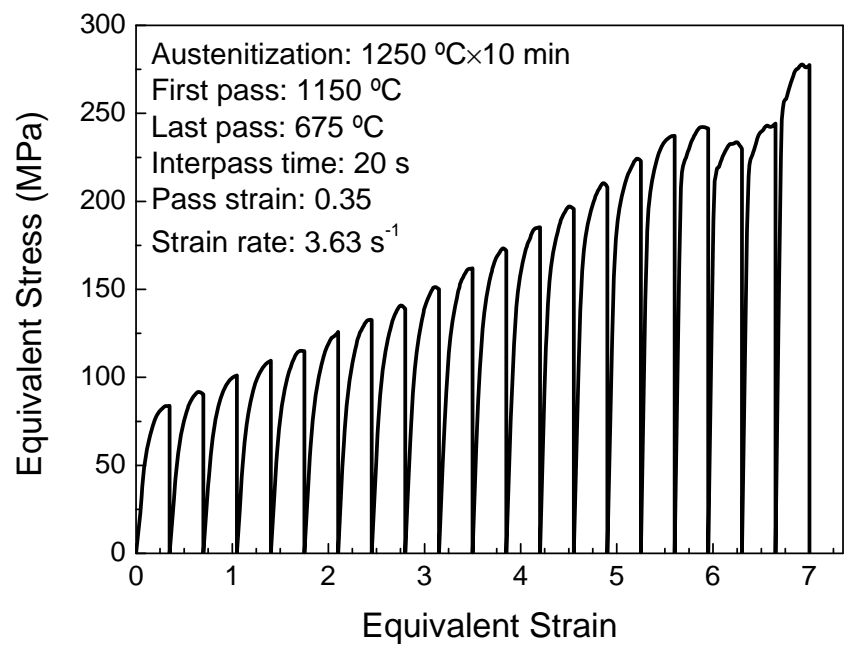

a)

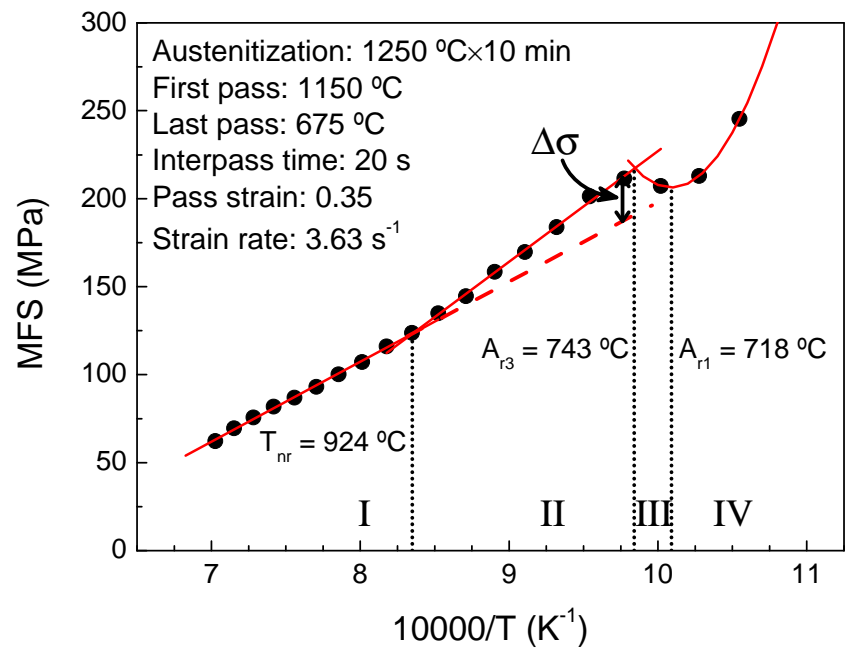

b) 


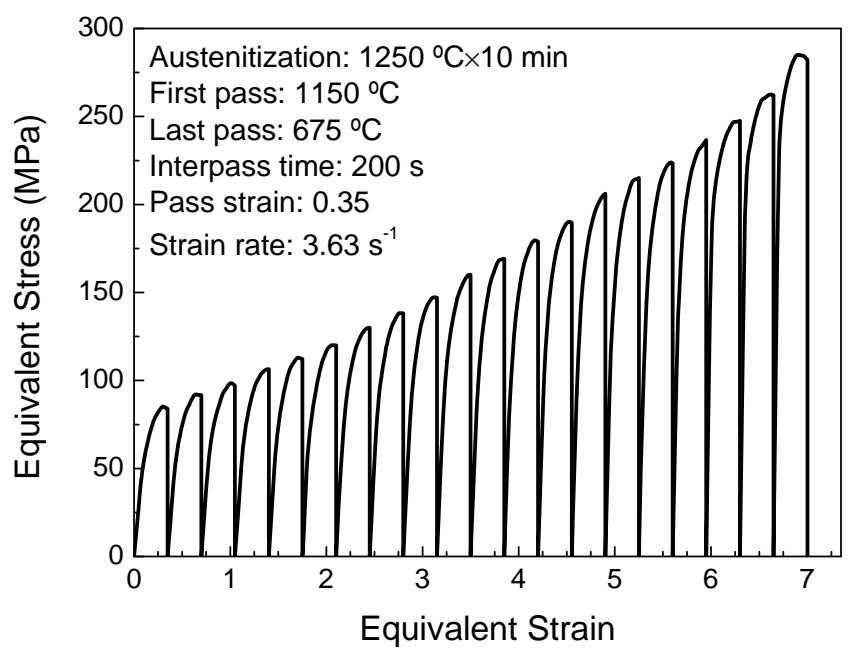

c)

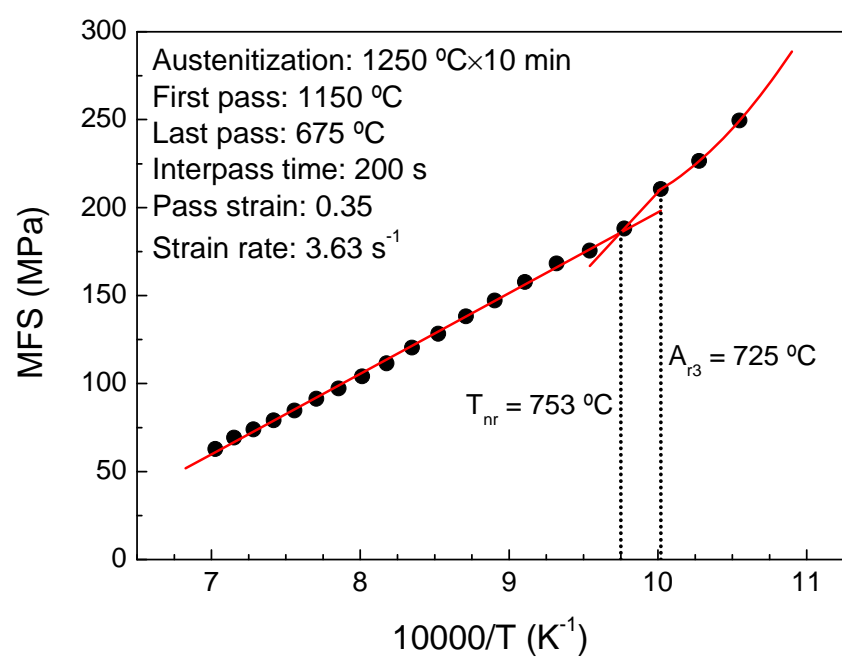

d)

Fig. 3. Multipass hot rolling simulations by hot torsion, $\varepsilon=0.35 ; \dot{\varepsilon}=3.63 \mathrm{~s}^{-1}$. a) Stressstrain curves, $\Delta t=20 \mathrm{~s}$; b) Mean flow stress versus the inverse of absolute temperature, $\Delta \mathrm{t}=20 \mathrm{~s}$; c) Stress-strain curves, $\Delta \mathrm{t}=200 \mathrm{~s}$; d) Mean flow stress versus the inverse of absolute temperature, $\Delta \mathrm{t}=200 \mathrm{~s}$. 


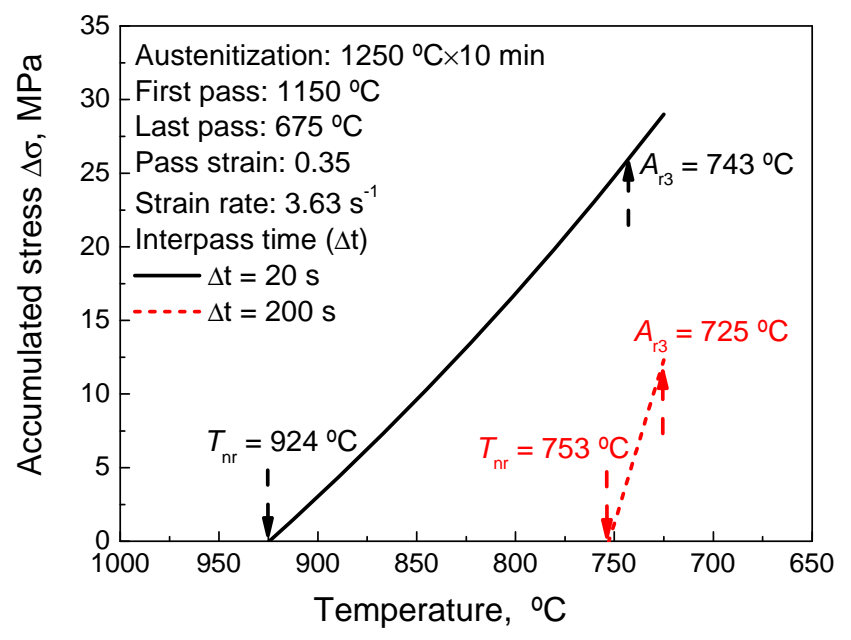

Fig. 4. Evolution of austenite accumulated stress $(\Delta \sigma)$ during hot rolling for the two interpass times used. 


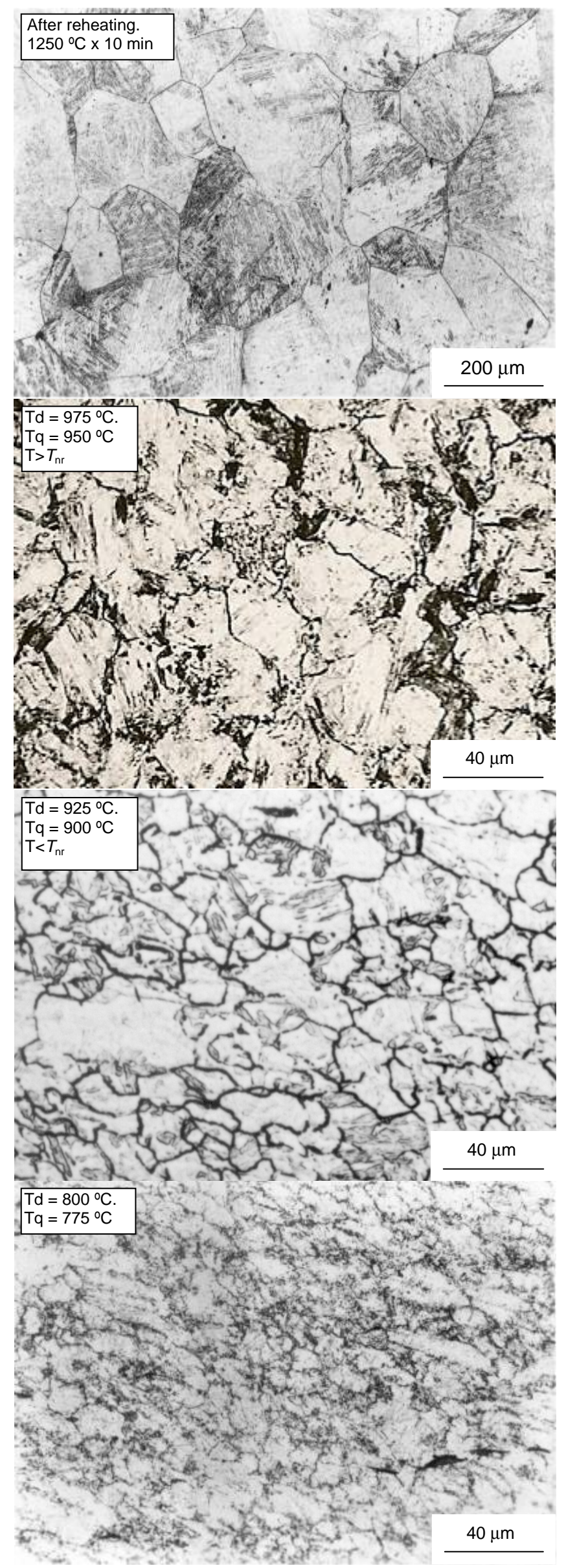


Fig. 5. Microstructures obtained at different stages of hot rolling simulation. $\varepsilon=0.35 ; \dot{\varepsilon}$ $=3.63 \mathrm{~s}^{-1} ; \Delta \mathrm{t}=20 \mathrm{~s}$; “Td” means deformation temperature and “Tq” quenching temperature. 


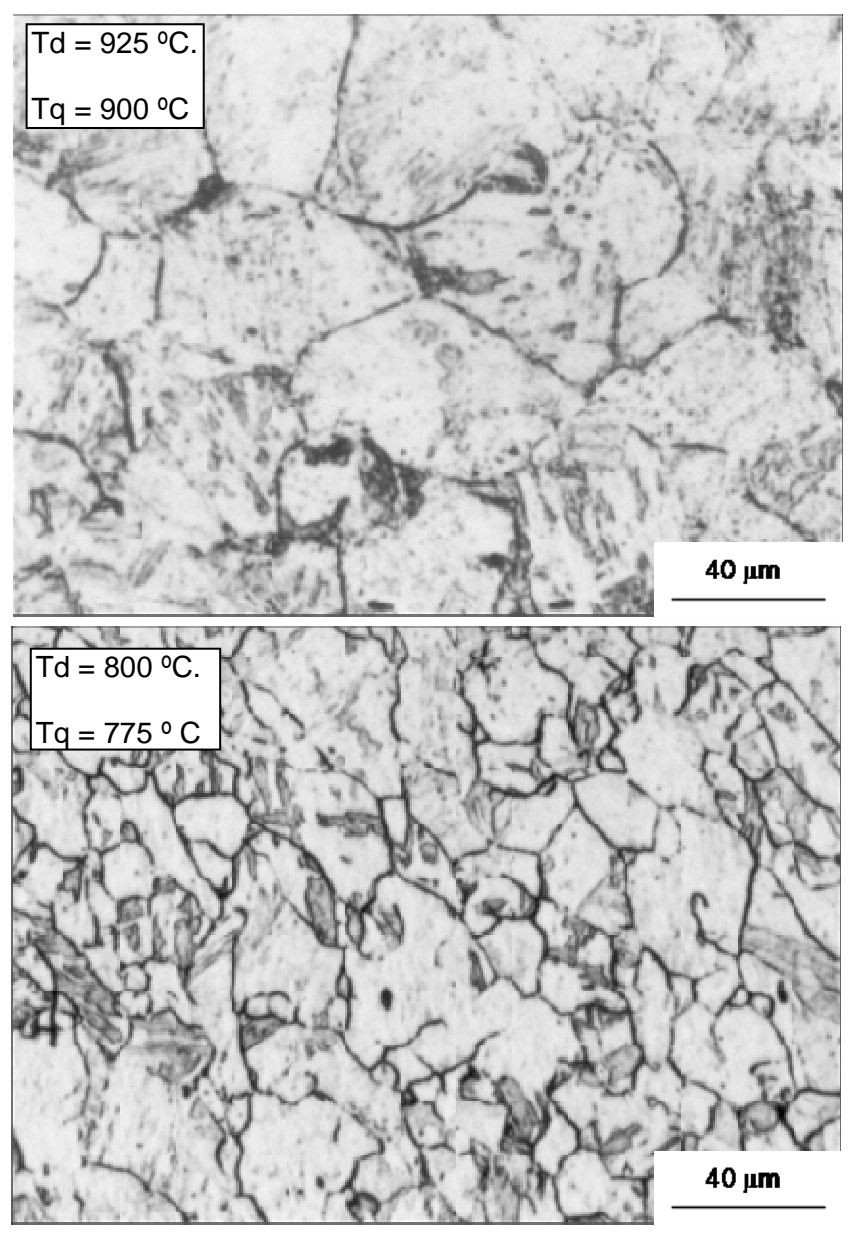

Fig. 6. Microstructures obtained at two stages of hot rolling simulation. $\varepsilon=0.35$; $\dot{\varepsilon}=$ $3.63 \mathrm{~s}^{-1} ; \Delta \mathrm{t}=200 \mathrm{~s}$; “Td” means deformation temperature and "Tq" quenching temperature. 


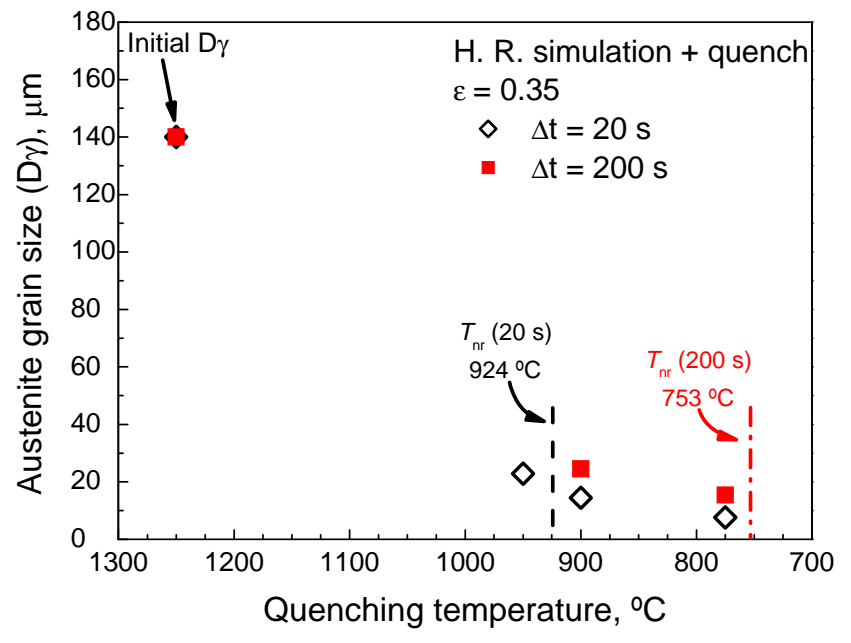

a)

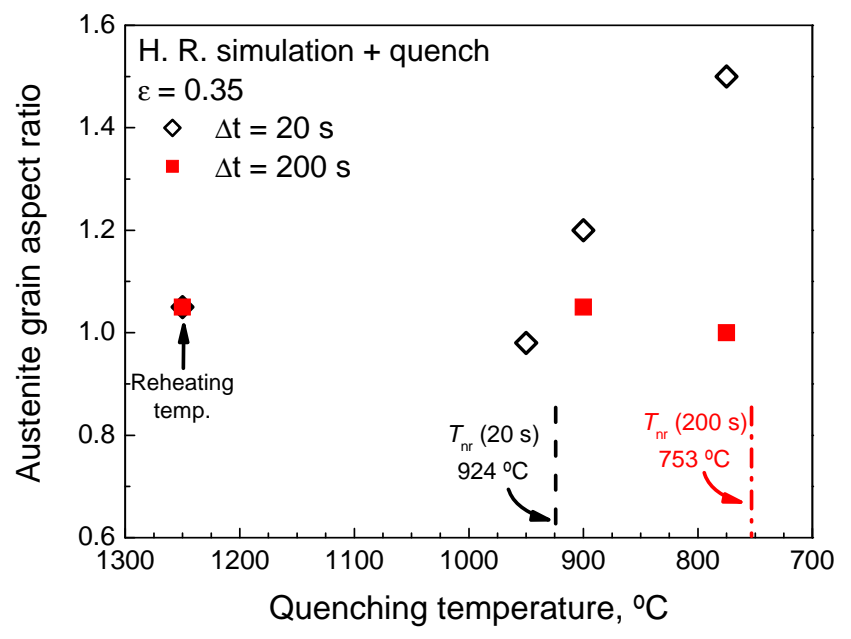

b)

Fig. 7. Evolution of austenite microstructure during hot rolling simulation for the two interpass times applied. a) Average austenite grain size. b) Average austenite grain aspect ratio. 


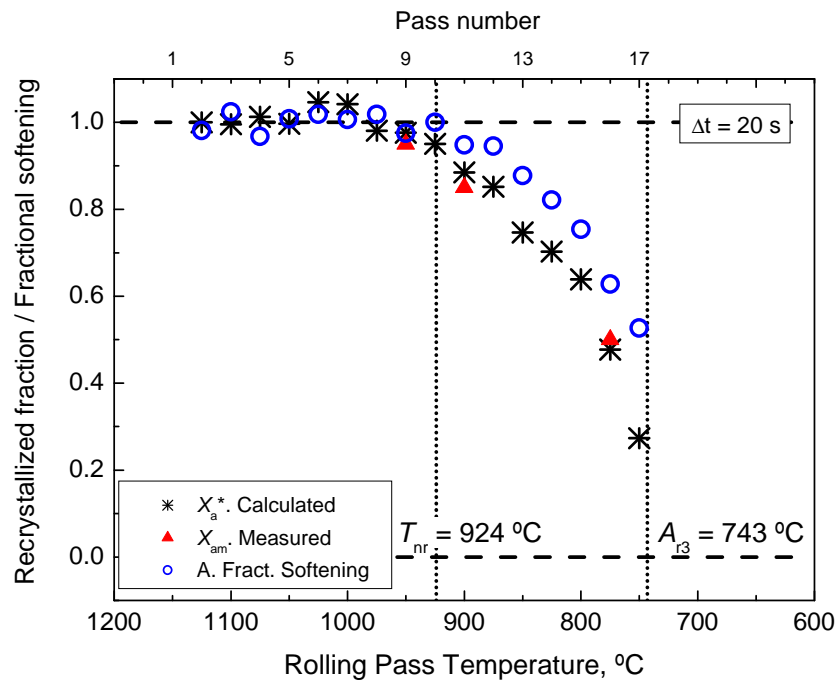

a)

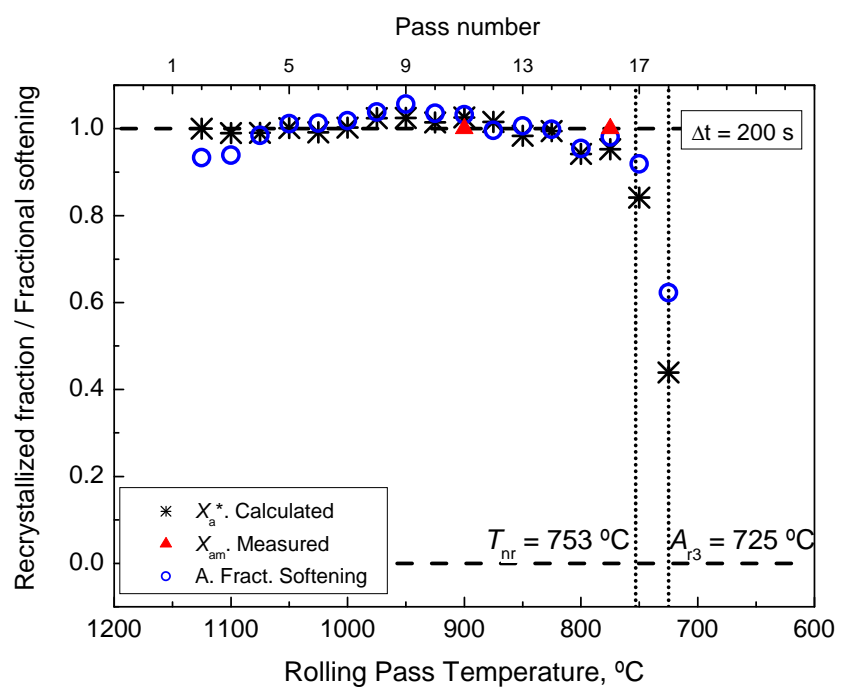

b)

Fig. 8. Estimation of statically recrystallized fraction $\left(X_{\mathrm{a}}^{*}\right)$ during hot rolling simulation using Eqs. (3)-(7). Comparison with experimental values measured by optical microscopy $\left(X_{\mathrm{am}}\right)$ and non-isothermal fractional softening measured with Eq. (9). $\varepsilon=$

$$
\left.0.35, \dot{\varepsilon}=3.63 \mathrm{~s}^{-1} \text {. a) } \Delta \mathrm{t}=20 \mathrm{~s} ; \mathbf{b}\right) \Delta \mathrm{t}=200 \mathrm{~s}
$$




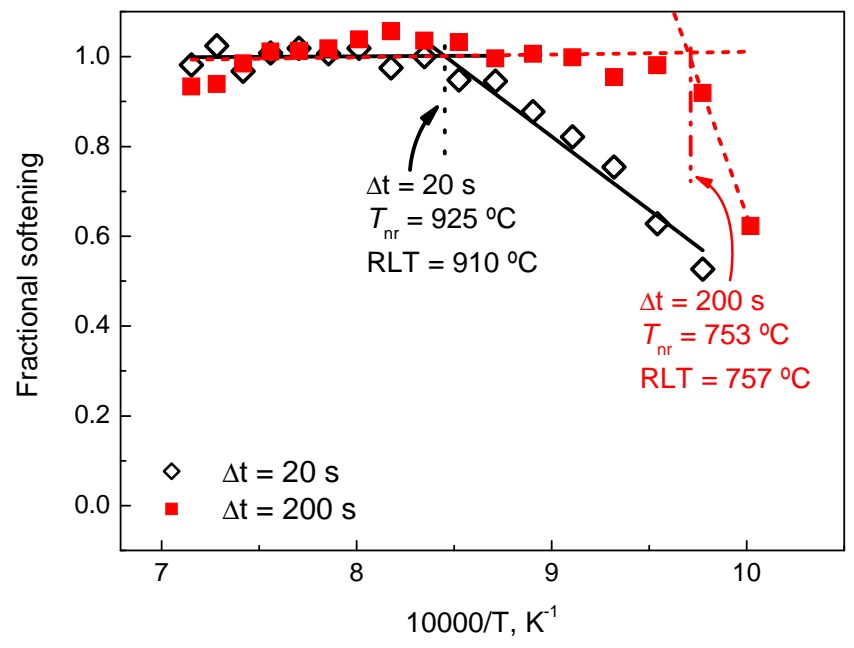

Fig. 9. Non-isothermal fractional softening versus the inverse of pass absolute temperature for the two interpass times applied. 